\title{
AVALIAÇÃO DE ASPECTOS BIOCLIMÁTICOS EM HABITAÇÕES SOCIAIS NO LITORAL SUL DA BAHIA
}

\author{
Calline Chaves de Jesus* \\ Heleonora Ferreira da Silva** \\ Silvia Kimo Costa***
}

RESUMO: Este artigo apresenta os resultados da pesquisa intitulada: "Habitações de Interesse Social (HIS) e eficiência energética: estudo de tipologias arquitetônicas no Litoral Sul da Bahia”. Foi realizado um diagnóstico de dois conjuntos habitacionais padrão construídos entre os anos de 2009 e 2017 nos municípios de Ilhéus e Itabuna, BA. Tais empreendimentos estão vinculados ao Programa Habitacional do Governo Federal "Minha Casa Minha Vida" (PMCMV) e atendem o estrato da população que se enquadra na faixa de renda de zero a três salários mínimos. Para realizar tal diagnóstico foi elaborado um roteiro de observação direcionado a partir de um Estudo de Revisão Sistemática relacionado às estratégias que possibilitam eficiência energética em HIS. Os resultados mostraram que a arquitetura habitacional padrão do PMCMV, que vem sendo construída no litoral sul da Bahia, não contempla estratégias de sustentabilidade mínimas para viabilizar o conforto ambiental com menor dispêndio de energia.

PALAVRAS-CHAVE: Habitações de interesse social; Sustentabilidade; Estudo de revisão sistemática.

\section{EVALUATION OF BIOCLIMATIC ASPECTS IN SOCIAL HOUSING ESTATES IN THE SOUTHERN COAST OF BAHIA, BRAZIL}

ABSTRACT: Current paper provides the results of the research 'Social Housing estates and energy efficiency: study on the architectonic typology on the south coast of Bahia, Brazil'. Two housing estates built between 2009 and 2017 in Ilheus and Itabuna were investigated. The enterprises are part of the Housing Program of

\footnotetext{
*Discente do Curso de segundo ciclo de formação em Engenharia Florestal da Universidade Federal do Sul da Bahia, Brasil.

** Discente do Curso de segundo ciclo de formação em Direito da Universidade Federal do Sul da Bahia, Brasil.

**** Doutora em Desenvolvimento e Meio Ambiente e Docente do Centro de Formação em Ciências Agroflorestais da Universidade Federal do Sul da Bahia, Brasil. E-mail: skcosta@ufsb.edu.br
} 
the Federal Government "Minha Casa Minha Vida" (PMCMV) and are beneficent to people earning up to three minimum wages. An observation scheme was prepared as from the Study of Systematic Review related to strategies that make possible energy efficiency on the estates. Results show that the housing architecture under analysis, built in southern Bahia, failed sustainability strategies to make available comfort with low energy costs.

KEY WORDS: Social housing estates; Sustainability; Systematic review.

\section{INTRODUÇÃO}

O presente artigo apresenta os resultados da pesquisa intitulada: "Habitações de Interesse Social (HIS) e eficiência energética: estudo de tipologias arquitetônicas no Litoral Sul da Bahia". A pesquisa foi desenvolvida entre os meses de agosto de 2017 e agosto de 2018 e objetivou analisar aspectos bioclimáticos projetuais em conjuntos habitacionais do Programa Minha Casa Minha Vida (para a faixa de renda de 0 a 3 salários mínimos) que foram construídos entre os anos de 2009 e 2017 nos municípios de Ilhéus e Itabuna, BA.

Pontua-se que a construção de Habitações de Interesse Social (HIS) está vinculada a políticas públicas que objetivam sanar o déficit habitacional pela provisão de moradias dignas e sustentáveis para pessoas que se enquadram em situação de extrema vulnerabilidade social. Nesse contexto, o Programa Minha Casa Minha Vida (PMCMV), criado em 2009, constituiu e é, até o presente momento, um dos programas habitacionais mais incisivos no que tange à redução do déficit habitacional brasileiro (CARVALHO; STEPHAN, 2016).

Entretanto, além de o programa pautar-se num modelo de inclusão pelo consumo e corroborar a reprodução periférica da moradia da população de baixa renda no país (ROLNIK et al., 2015), o padrão arquitetônico das habitações do PMCMV, no que tange o atendimento a essa população, não vem considerando a diversidade de realidades socioespaciais e necessidades dos demandantes (REIS; LAYS, 2010) e segundo Cota e Silva (2016), não apresenta inovações no design e estratégias de sustentabilidade arquitetônica.

Considerando o exposto, a pesquisa, porém, partiu da hipótese de que as 
condições biogeoclimáticas do litoral sul da Bahia (alto índice de incidência solar; alto índice pluviométrico; grandes áreas de preservação da Mata Atlântica) potencializam estratégias projetuais que contemplam aspectos bioclimáticos, contribuindo para um padrão habitacional do PMCMV, na referida região, que viabiliza eficiência energética.

A metodologia abrangeu três etapas: na primeira foi desenvolvido um Estudo de Revisão Sistemática (ERS) - Systematic Literature Review - considerando especificamente a análise de referências publicadas entre os anos de 2007 e 2017 e que abordam a sustentabilidade em habitações de interesse social com enfoque em bioclimática e eficiência energética. Na segunda etapa foi elaborado um Roteiro de Observação Direcionado com base no ERS. Por fim, na terceira etapa, procedeu-se com o trabalho de campo e aplicação do referido roteiro de observação para análise dos conjuntos habitacionais selecionados para a pesquisa.

O artigo está organizado em três seções: a primeira aborda os principais conceitos norteadores da pesquisa; a segunda descreve a metodologia e a terceira apresenta os principais resultados.

\section{DESENVOLVIMENTO}

\subsection{CONCEITOS NORTEADORES}

\subsubsection{Habitação de Interesse Social, Arquitetura Sustentável, Eficiência Energética e Estratégias Bioclimáticas}

O termo Habitação de Interesse Social (HIS) refere-se a uma série de soluções de moradia voltada para a população de baixa renda (BALBIM; KRAUSE, 2014; RUBIN, 2013). Em âmbito internacional, o termo é conhecido como Lowincome Housing (ORLEBEKE, 2010). No Brasil, as HIS estão relacionadas ao déficit habitacional, que pode ser entendido como, déficit por reposição de estoque e déficit por incremento de estoque de moradias (FUNDAÇÃO JOÃO PINHEIRO, 2016). Refere-se ao atendimento à população de baixa renda que reside em áreas urbanas 
não adequadas para fins residenciais; em habitações extremamente precárias; em habitações coabitadas por várias famílias e, em habitações cujo custo do aluguel é excessivamente alto em relação à renda do/a morador/a.

A pesquisa considerou os conjuntos habitacionais do PMCMV construídos para atender a população que se enquadra no déficit habitacional quantitativo dos municípios de Ilhéus e Itabuna, BA - faixa 1 do programa habitacional: renda de zero a três salários mínimos.

Por arquitetura sustentável entende-se

[...] a continuidade mais natural da Bioclimática, considerando também a integração do edifício à totalidade do meio ambiente, de forma a torná-lo parte de um conjunto maior. É a arquitetura que quer criar prédios objetivando o aumento da qualidade de vida do ser humano no ambiente construído e no seu entorno, integrando com as características da vida e do clima locais, consumindo a menor quantidade de energia compatível com o conforto ambiental, para legar um mundo menos poluído para as futuras gerações. (CORBELLA; YANNAS, 2009, p. 19).

Ou seja, a pesquisa pautou-se numa vertente conceitual relacionada à arquitetura austentável que está diretamente associada ao uso de estratégias bioclimáticas e eficiência energética.

A eficiência energética em edificações acontece quando é possível manter o conforto higrotérmico com menor consumo de energia (CORBELLA; CORNER, 2011) e pode ser viabilizada por meio do uso de estratégias bioclimáticas (passivas e ativas) durante a elaboração do projeto arquitetônico.

As estratégias bioclimáticas, por sua vez, são aquelas que incorporam, ao processo de projeto arquitetônico de uma edificação, características biogeoclimáticas do local onde a mesma será construída (FOSTER; HAWKES, 2002).

Kibert (2013) e Duran (2011) elencam algumas das principais estratégias bioclimáticas passivas e ativas: a) considerar temperatura e umidade locais, incidência solar, direção dos ventos; orografia para termorregulação dos ambientes internos; b) uso de materiais de construção alternativos com alta massa térmica, capacidade de dilatação e de baixo impacto ambiental; c) utilizar vegetação para 
moderação do microclima, tais como telhado verde e fachada verde que possibilitam um sistema de controle térmico que purifica o ar, refresca os ambientes internos da edificação durante o dia e regula a mudança de temperatura durante a noite; d) propor envelopamento de fachadas para redução de consumo de energia e promover regulação da temperatura durante as mudanças climáticas; e) viabilizar o suprimento de energia através de fontes de energia renovável (uso de painéis fotovoltaicos; energia termossolar, eólica, hidro e geotérmica e o uso da biomassa).

Segundo Santesso et al. (2017), a utilização de estratégias bioclimáticas passivas e ativas no processo de projeto de habitações de interesse social, principalmente aquelas vinculadas ao PMCMV, contribui para melhoria do desempenho ambiental das moradias e racionalização no uso de energia elétrica sem comprometer o conforto higrotérmico dos ambientes.

Além das estratégias bioclimáticas, é pertinente considerar que a redução do consumo de água e o gerenciamento sustentável dos resíduos sanitários também estão associados à sustentabilidade arquitetônica em habitações de interesse social.

Segundo Marcena et al. (2017), a redução do consumo de água pode ser viabilizada pela coleta e pelo armazenamento de águas pluviais para reúso não potável e o gerenciamento sustentável dos resíduos sanitários pode ser realizado por meio das Wetlands - "[...] estratégia de tratamento que utiliza ecossistemas artificiais com diferentes tecnologias, por meio de princípios básicos de modificação de qualidade da água das Wetlands naturais." (SALATI, 2006, p. 5).

Pontua-se que os conceitos apresentados nessa seção nortearam o estudo de revisão sistemática e, consequentemente, a elaboração do roteiro de observação direcionado para análise dos conjuntos habitacionais selecionados para a pesquisa.

\subsection{METODOLOGIA}

\subsubsection{Etapa 1 - Estudo de Revisão Sistemática}

Segundo Tranfield, Denyer e Smart (2003), uma Systematic Literature Review - Estudo de Revisão Sistemática (ERS) - é um meio de identificar, avaliar e interpretar todas as pesquisas disponíveis relevantes para uma determinada questão/ 
hipótese de pesquisa, área de tópico ou fenômeno de interesse. Estudos individuais que contribuem para uma revisão sistemática são denominados estudos primários; uma revisão sistemática é uma forma de estudo secundário.

O ERS desenvolvido durante a pesquisa contemplou a busca por publicações científicas relacionadas à sustentabilidade das habitações de interesse social. Para selecioná-las foram definidos os seguintes critérios de inclusão: a) ser referência publicada entre os anos de 2007 e 2017 e; b) ser referência que abordasse sustentabilidade em habitações de interesse social com enfoque em estratégias bioclimáticas e eficiência energética.

O intervalo de tempo para seleção das publicações foi estipulado de modo a englobar anos anteriores e posteriores ao início de construção dos empreendimentos do PMCMV (para a faixa de renda de 0 a 3 salários mínimos) nos municípios de Ilhéus e Itabuna, BA. Os empreendimentos começaram a ser construídos a partir de 2009 nos referidos municípios.

Ao todo foram selecionadas cerca de 20 referências para análise entre dissertações, teses, artigos publicados em revistas científicas e artigos publicados em eventos científicos nacionais e internacionais (Quadro 1).

Quadro 1. Publicações científicas selecionadas para análise durante o ERS (Continua)

\begin{tabular}{|c|l|l|c|c|}
\hline Ref. & \multicolumn{1}{|c|}{ Autores } & \multicolumn{1}{|c|}{ Título da publicação } & $\begin{array}{c}\text { Modalidade da } \\
\text { publicação }\end{array}$ & $\begin{array}{c}\text { Data da } \\
\text { publicação }\end{array}$ \\
\hline 1 & $\begin{array}{l}\text { SOUZA, M. C de.; } \\
\text { GRIGOLETTI, G.; VA- } \\
\text { GHETTI, M. O. }\end{array}$ & $\begin{array}{l}\text { Avaliações dinâmicas da ilumina- } \\
\text { ção natural em protótipo de habi- } \\
\text { tação de interesse social. }\end{array}$ & $\begin{array}{c}\text { Congresso Inter- } \\
\text { nacional }\end{array}$ & 2017 \\
\hline 2 & $\begin{array}{l}\text { MORAIS, J. M. da S. } \\
\text { C.; LABAKI, L. C. }\end{array}$ & $\begin{array}{l}\text { CFD como ferramenta para simu- } \\
\text { lar ventilação natural interna por } \\
\text { em tipologias verticais do "Progra- } \\
\text { ma Minha Casa, Minha Vida". }\end{array}$ & $\begin{array}{l}\text { Revista Científica } \\
\text { Nacional }\end{array}$ & 2017 \\
\hline 3 & $\begin{array}{l}\text { PROVENZANO, D. de } \\
\text { C.; BASTOS, L. E. G. }\end{array}$ & $\begin{array}{l}\text { Avaliação da sustentabilidade de } \\
\text { um empreendimento de HIS do } \\
\text { PMCMV, através do Selo Casa Azul. }\end{array}$ & $\begin{array}{r}\text { Revista Científica } \\
\text { Nacional }\end{array}$ & 2017 \\
\hline
\end{tabular}


(Continua)

\begin{tabular}{|c|c|c|c|c|}
\hline Ref. & Autores & Título da publicação & $\begin{array}{l}\text { Modalidade da } \\
\text { publicação }\end{array}$ & $\begin{array}{c}\text { Data da } \\
\text { publicação }\end{array}$ \\
\hline 4 & $\begin{array}{l}\text { SANTOS, R. L. dos.; } \\
\text { SANTANA, J. C. S. }\end{array}$ & $\begin{array}{l}\text { Materiais de construção susten- } \\
\text { táveis em empreendimentos de } \\
\text { habitação de interesse social finan- } \\
\text { ciados pelo PMCMV. }\end{array}$ & $\begin{array}{l}\text { Revista Científica } \\
\text { Nacional }\end{array}$ & 2017 \\
\hline 5 & $\begin{array}{l}\text { MACHADO, R. M e } \\
\text { S.; VAGHETTI, M. A. } \\
\text { O. }\end{array}$ & $\begin{array}{l}\text { Casa popular eficiente: desempe- } \\
\text { nho térmico durante o inverno. }\end{array}$ & $\begin{array}{l}\text { Congresso Re- } \\
\text { gional }\end{array}$ & 2015 \\
\hline 6 & RIOS, G. A de A. & $\begin{array}{l}\text { Desempenho Termoenergético de } \\
\text { habitação de interesse social. }\end{array}$ & Tese Doutorado & 2015 \\
\hline 7 & $\begin{array}{lll}\text { SPOSTO, } & \text { R. } & \text { M.; } \\
\text { PAULSEN, J. S. } & \end{array}$ & $\begin{array}{l}\text { Energia incorporada em habita- } \\
\text { ções de interesse social na fase } \\
\text { de pré-uso: o caso do Programa } \\
\text { Minha Casa Minha Vida no Brasil. }\end{array}$ & $\begin{array}{l}\text { Revista Científica } \\
\text { Nacional }\end{array}$ & 2014 \\
\hline 8 & $\begin{array}{l}\text { SANTOS, K. F dos.; } \\
\text { OLIVEIRA, D, M. de.; } \\
\text { NUNES, L. A. M. }\end{array}$ & $\begin{array}{l}\text { Sustentabilidade na construção de } \\
\text { residências para o projeto "Minha } \\
\text { Casa Minha Vida". }\end{array}$ & $\begin{array}{l}\text { Congresso Na- } \\
\text { cional }\end{array}$ & 2014 \\
\hline 9 & $\begin{array}{l}\text { MORAIS, J. M. da S. } \\
\text { C. }\end{array}$ & $\begin{array}{l}\text { Ventilação natural em edificios } \\
\text { multifamiliares do "Programa Mi- } \\
\text { nha Casa Minha Vida". }\end{array}$ & Tese Doutorado & 2013 \\
\hline 10 & $\begin{array}{l}\text { SARAMAGO, R de C. } \\
\text { P.; VILLA, S. B. }\end{array}$ & $\begin{array}{l}\text { Estratégias de sustentabilidade } \\
\text { para habitação social: a experiên- } \\
\text { cia do Projeto Mora. }\end{array}$ & $\begin{array}{l}\text { Congresso Inter- } \\
\text { nacional }\end{array}$ & 2013 \\
\hline 11 & $\begin{array}{l}\text { ROCHA, F. M. D.; } \\
\text { MELO, A. B.; SILVA, } \\
\text { E. P.; TORRES, S. M. }\end{array}$ & $\begin{array}{l}\text { Pré-moldado (bloco EVAi) para al- } \\
\text { venaria intertravada: projeto, pro- } \\
\text { dução, desempenho e simulação } \\
\text { de uso em habitação social. }\end{array}$ & $\begin{array}{l}\text { Revista Científica } \\
\text { Nacional }\end{array}$ & 2013 \\
\hline 12 & $\begin{array}{l}\text { BRASILEIRO, S. B. } \\
\text { de C. }\end{array}$ & $\begin{array}{l}\text { Adequação ao selo Casa Azul da } \\
\text { Caixa Econômica Federal de edi- } \\
\text { ficações do Programa Minha Casa } \\
\text { Minha Vida. }\end{array}$ & $\begin{array}{l}\text { Dissertação } \\
\text { Mestrado }\end{array}$ & 2013 \\
\hline 13 & $\begin{array}{l}\text { SOBREIRA, F.; FE- } \\
\text { LIX, B. }\end{array}$ & $\begin{array}{l}\text { Projetos de habitação social no } \\
\text { Brasil: discurso e prática da sus- } \\
\text { tentabilidade. }\end{array}$ & $\begin{array}{l}\text { Revista Científica } \\
\text { Nacional }\end{array}$ & 2013 \\
\hline
\end{tabular}


(Conclusão)

\begin{tabular}{|c|c|c|c|c|}
\hline Ref. & Autores & Título da publicação & $\begin{array}{l}\text { Modalidade da } \\
\text { publicação }\end{array}$ & $\begin{array}{c}\text { Data da } \\
\text { publicação }\end{array}$ \\
\hline 14 & $\begin{array}{l}\text { CARVALHO, M. T.M.; } \\
\text { SPOSTO, R. M. }\end{array}$ & $\begin{array}{l}\text { Metodologia para avaliação da sus- } \\
\text { tentabilidade de habitações de in- } \\
\text { teresse social com foco no projeto. }\end{array}$ & $\begin{array}{c}\text { Revista Científica } \\
\text { Nacional }\end{array}$ & 2012 \\
\hline 15 & $\begin{array}{l}\text { VISINTAINER, M. R. } \\
\text { M.; CARDOSO, L. A.; } \\
\text { VAGHETTI, M. A. O. }\end{array}$ & $\begin{array}{l}\text { Habitação popular sustentável: } \\
\text { sustentabilidade econômica e am- } \\
\text { biental. }\end{array}$ & $\begin{array}{c}\text { Revista Científica } \\
\text { Nacional }\end{array}$ & 2012 \\
\hline Ref. & Autores & Título da publicação & $\begin{array}{l}\text { Modalidade da } \\
\text { publicação }\end{array}$ & $\begin{array}{c}\text { Data da } \\
\text { publicação }\end{array}$ \\
\hline 16 & $\begin{array}{l}\text { OLIVEIRA, E. W. } \mathrm{N} \\
\text { de. }\end{array}$ & $\begin{array}{l}\text { Telhados verdes para habitações } \\
\text { de interesse social: retenção das } \\
\text { águas pluviais e conforto térmico. }\end{array}$ & $\begin{array}{c}\text { Dissertação } \\
\text { Mestrado }\end{array}$ & 2009 \\
\hline 17 & $\begin{array}{l}\text { KRÜGER, E. L.; LA- } \\
\text { ROCA, C. }\end{array}$ & $\begin{array}{l}\text { Avaliação de desempenho térmico } \\
\text { de protótipo de baixo custo em } \\
\text { madeira de reflorestamento. }\end{array}$ & $\begin{array}{c}\text { Revista Científica } \\
\text { Nacional }\end{array}$ & 2009 \\
\hline 18 & $\begin{array}{l}\text { BARBOSA, A da S. R.; } \\
\text { BARBIRATO, J. C. C.; } \\
\text { SILVA, M. M. C. P. }\end{array}$ & $\begin{array}{l}\text { Avaliação do uso de bambu como } \\
\text { material alternativo para a execu- } \\
\text { ção de habitação de interesse so- } \\
\text { cial. }\end{array}$ & $\begin{array}{c}\text { Revista Científica } \\
\text { Nacional }\end{array}$ & 2008 \\
\hline 19 & ASSIS et al. & $\begin{array}{l}\text { Habitação social e eficiência ener- } \\
\text { gética: um protótipo para o clima } \\
\text { de Belo Horizonte. }\end{array}$ & $\begin{array}{l}\text { Congresso Na- } \\
\text { cional }\end{array}$ & 2007 \\
\hline 20 & BOHADANA, I. P.B. & $\begin{array}{l}\text { Avaliação de habitação de interesse } \\
\text { social rural construída com fardos } \\
\text { de palha, terra e cobertura verde, } \\
\text { segundo critérios de sustentabili- } \\
\text { dade. }\end{array}$ & $\begin{array}{l}\text { Dissertação } \\
\text { Mestrado }\end{array}$ & 2007 \\
\hline
\end{tabular}

Pontua-se que as categorias do AQUA também foram consultadas. O AQUA é a primeira metodologia que contempla indicadores de sustentabilidade do ambiente construído adaptado ao contexto brasileiro. O sistema considera 15 aspectos a serem analisados vinculados a quatro indicadores (GRÜNBERG; MEDEIROS; TAVARES, 2014):

Indicador Eco construção: 1) relação do edifício com o entorno, 2) escolha integrada de produtos, 3) sistemas e processos. 
Indicador gestão: 4) gestão de energia, 5) gestão de água, 6) gestão dos resíduos do uso e ocupação do solo, 7) manutenção, 8) canteiro de obra com baixo impacto ambiental.

Indicador conforto ambiental: 9) conforto higrotérmico, 10) conforto acústico, 11) conforto visual, 12) conforto olfativo.

Indicador saúde: 13) qualidade sanitária dos ambientes; 14) qualidade sanitária do ar e 15) qualidade sanitária da água.

\subsubsection{Etapa 2 - Elaboração do Roteiro de Observação Direcionado}

Após a análise das referências selecionadas por meio do ERS e análise da metodologia do AQUA, procedeu-se com a elaboração do Roteiro de Observação Direcionado (Anexo 1). Este último considerou as seguintes categorias de avaliação: 1) implantação do conjunto habitacional; 2) planta baixa padrão; 3) sombreamento de fachadas; 4) materiais usados na construção; 5) presença de vegetação; 6) tipo de pavimentação; 7) utilização de fontes alternativas para geração de energia; 8) coleta e armazenamento das águas pluviais para reúso não potável; 9) tratamento de resíduos sanitários e domésticos.

\subsubsection{Etapa 3 - Trabalho de Campo}

Segundo Ramos e Noia (2014), a partir do ano de 2010, foi contratada a construção de sete conjuntos habitacionais do PMCMV no município de Ilhéus, BA e a partir de 2009 cerca de nove conjuntos habitacionais no município de Itabuna, BA (Quadro 2). Todos destinados ao atendimento da população na faixa de renda de zero a três salários mínimos. A conclusão das obras ocorreu entre os anos de 2014 e 2017. 
Quadro 2. Conjuntos habitacionais do PMCMV (Faixa 1-de 0 a 3 salários mínimos) contratados para construção em Ilhéus e Itabuna, BA entre 2009 e 2014

\begin{tabular}{|l|c|c|}
\hline \multicolumn{1}{|l|}{ Município de Ilhéus, BA } \\
\hline \multicolumn{1}{|c|}{ Nome do conjunto habitacional } & Faixa de atendimento & Início da obra \\
\hline Condomínio Residencial Morada das Águas II & 0 a 3 salários mínimos & 2010 \\
\hline Residencial Morada das Águas I & 0 a 3 salários mínimos & 2010 \\
\hline Residencial Morada da Brisas & 0 a 3 salários mínimos & 2010 \\
\hline Residencial Morada do Porto & 0 a 3 salários mínimos & 2010 \\
\hline Residencial Sol e Mar etapa 1 & 0 a 3 salários mínimos & 2014 \\
\hline Residencial Sol e Mar etapa 2 & 0 a 3 salários mínimos & 2014 \\
\hline Residencial Vilela & 0 a 3 salários mínimos & 2014 \\
\hline Município de Itabuna, BA & Faixa de atendimento & Início da obra \\
\hline \multicolumn{1}{|c|}{ Nome do conjunto habitacional } & 0 a 3 salários mínimos & 2010 \\
\hline Residencial Itabuna Parque & 0 a 3 salários mínimos & 2011 \\
\hline Residencial Jardim América & 0 a 3 salários mínimos & 2009 \\
\hline Residencial Pedro Fontes de Araújo I & 0 a 3 salários mínimos & 2009 \\
\hline Residencial Pedro Fontes de Araújo II & 0 a 3 salários mínimos & 2009 \\
\hline Residencial Vida Nova - Etapa 1 & 0 a 3 salários mínimos & 2013 \\
\hline Conjunto Habitacional Jardim América Etapa II & 0 a 3 salários mínimos & 2013 \\
\hline Conjunto Habitacional São José & 0 a 3 salários mínimos & 2014 \\
\hline Residencial Gabriela & 0 a salários mínimos & 2014 \\
\hline Residencial Jubiabá & Noia (2014, p. 11-14). \\
\hline Fonte: Elaborado pelos autores com base em Ramos e & \\
\hline
\end{tabular}

Tais empreendimentos apresentam duas tipologias de planta baixa padrão (Figuras 1 e 2). A primeira para apartamentos geminados de edificações de até dois pavimentos e a segunda para apartamentos geminados de edificações de até quatro pavimentos.

Foram escolhidos para análise in loco, o Residencial Pedro Fontes de Araújo I, concluído em 2013, localizado em Itabuna, BA (Figura 3) e o Residencial Rio Cachoeira localizado em Ilhéus, BA (Figura 4), cuja construção foi iniciada em 2015 e concluída em 2017 (posterior ao levantamento realizado por Ramos e Noia (2014)).

O primeiro é representativo de conjuntos habitacionais com planta baixa 
padrão para apartamentos geminados em edificações de quatro pavimentos (apartamentos de 43,50 $\mathrm{m}^{2}$ ) e o segundo é representativo de conjuntos habitacionais com planta baixa padrão para apartamentos geminados de dois pavimentos (apartamentos de 39,00 $\mathrm{m}^{2}$ ).

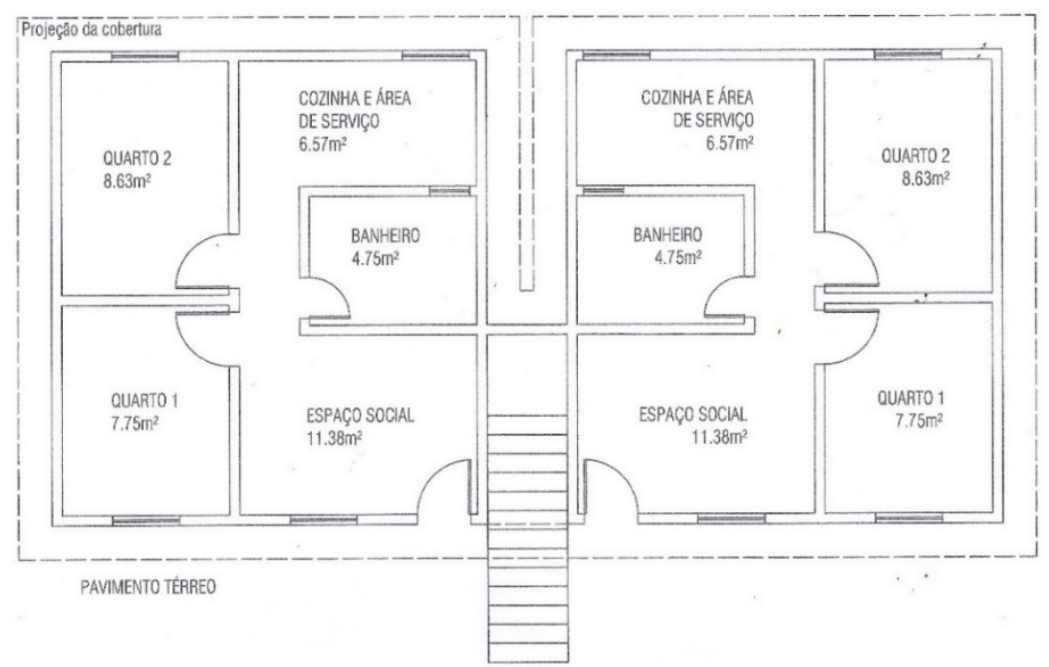

Figura 1. Planta baixa padrão para apartamentos geminados de edificações de dois pavimentos Fonte: elaborado por um dos autores (2018) 


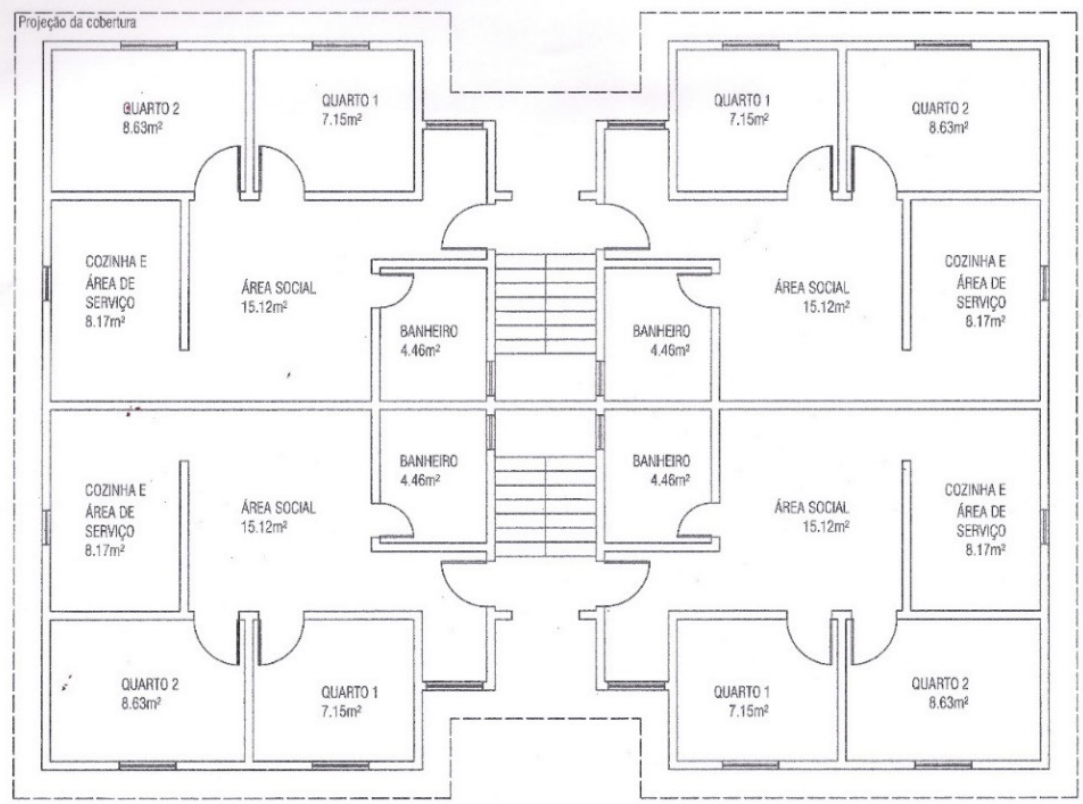

Figura 2. Planta baixa padrão para apartamentos geminados de edificações de quatro pavimentos Fonte: Do autor (2018)

O trabalho de campo para aplicação do roteiro de observação direcionado ocorreu entre abril e junho de 2018, no período diurno (manhã ou tarde) e em horários de menor trânsito de moradores.

Registra-se que a pesquisa não envolveu contato direto com qualquer morador dos conjuntos habitacionais analisados. A entrada nos empreendimentos é livre para público e as plantas padrão foram desenhadas com base no levantamento cadastral dos apartamentos decorados que se encontram disponíveis para visita pública.

\subsection{RESULTADOS E DISCUSSÕES}

Após visitas aos conjuntos habitacionais selecionados para pesquisa e aplicação do roteiro de observação direcionado verificou-se que: 
1. quanto à implantação dos conjuntos habitacionais: ambos foram implantados considerando parcialmente a topografia local, havendo alguns cortes e aterros - apresentam muros de contenção e taludes.

No que se refere ao posicionamento das edificações em relação ao sol, no Residencial Pedro Fontes de Araújo I foi observada considerável quantidade de fachadas onde a incidência solar é excessiva (fachadas expostas ao sol por mais de 4 horas diárias). Já no Residencial Rio Cachoeira a existência de arborização nativa em seu entorno imediato contribui para o sombreamento das edificações. Ambos foram construídos sem considerar a direção dos ventos dominantes locais.

Tanto o Residencial Pedro Fontes de Araújo I quanto o Residencial Rio Cachoeira estão localizados em áreas periféricas ao centro urbano dos municípios, e de seus respectivos serviços urbanos, cerca de $15 \mathrm{~km}$ ou mais. Segundo Souza e Sugai (2018), isso contribui para corroborar o processo de segregação socioespacial urbana.

2. quanto à análise da planta baixa padrão: a disposição geminada dos apartamentos em ambos conjuntos habitacionais prejudica a locação adequada das janelas, impedindo a ventilação natural cruzada. Não existem janelas superiores (próximas ao teto) para viabilizar o efeito chaminé (saída do ar quente). E em ambos existem janelas voltadas para o interior das edificações.

É pertinente apontar que, segundo a NBR 15.220-3 (ABNT, 2003), o litoral do sul da Bahia está situado na zona bioclimática 8 (ZB8). A região caracteriza-se pelo clima quente, úmido e subúmido, com temperaturas anuais variando entre $20^{\circ}$ e $30^{\circ} \mathrm{C}$, sendo maiores e com menor amplitude térmica na faixa costeira (SANTOS; FRANÇA, 2009).

Dentre as diretrizes especificadas pela NBR 15.220-3 (ABNT, 2003), para construção de habitações na ZB8, destacam-se: a) grandes aberturas para ventilação e sombreamento das mesmas; b) paredes e coberturas construídas com materiais leves e refletores; c) ventilação natural cruzada permanente como estratégia de condicionamento térmico passivo; d) durante as horas mais quentes recomendase o uso de ventiladores em concomitância com a ventilação natural cruzada e/ ou condicionadores de ar.

A ventilação natural cruzada é uma das estratégias mais sugeridas para 
moderar o microclima dos ambientes internos em uma edificação (MORAIS; LABAKI, 2017). De acordo com Morais $(2013$, p. 7) "[...] o aproveitamento apropriado das correntes de ar naturais pode reduzir o consumo de energia dos edifícios, por se tratar de um sistema passivo de condicionamento, uma vez que edifícios bem ventilados não necessitam de climatização artificial”. Dessa forma, ao inviabilizar estratégias bioclimáticas passivas mínimas, os apartamentos analisados não mantêm o conforto térmico sem o uso constante de condicionadores de ar, aumentando o consumo de energia elétrica.

3. quanto ao sombreamento das fachadas: em ambos os conjuntos habitacionais não foi verificado o uso de Brise Soleil ou suportes para o crescimento de plantas (fachadas verdes), para sombreamento das fachadas que estão expostas à incidência solar por mais de 4 horas.

4. quanto aos materiais utilizados na construção: as paredes foram construídas em alvenaria de blocos (de concreto) com acabamento com chapisco, reboco e pintura; as paredes de áreas molhadas foram revestidas até meia altura com cerâmica tipo A e teto com acabamento com reboco e pintura. As esquadrias são em alumínio com vidro sem venezianas e o piso é revestido com cerâmica tipo A.

De acordo com Santos e Santana (2017), o uso de materiais de construção alternativos (tijolos de adobe com acabamentos naturais, por exemplo) a materiais convencionais, cuja massa térmica associada à ventilação cruzada promovem o resfriamento do ambiente, possibilitariam conforto ambiental com menor consumo de energia.

5. quanto à presença de vegetação de pequeno, médio e grande porte: apesar do entorno imediato ao Residencial Rio Cachoeira apresentar arborização nativa, observou-se que há poucas áreas gramadas e arborizadas entre as edificações e vias de acesso. Já no Residencial Pedro Fontes de Araújo I, não existe arborização em seu entorno imediato e há somente áreas gramadas entre as edificações e vias de acesso. De acordo com Medeiros Raposo (2014), a falta de arborização impossibilita a moderação do microclima local. Em adição, o uso de telhados verdes também não foi considerado. De acordo com Oliveira (2009, p. 34) o telhado verde "[...] influi na retenção das águas pluviais, na insolação, no clima urbano, na biodiversidade e diminui a poluição do ar". 
6. quanto ao tipo de pavimentação: em ambos conjuntos habitacionais, as vias de acesso são pavimentadas com asfalto e as calçadas são de cimento com juntas secas de dilatação contribuindo para impermeabilização do solo que, segundo Fontes e Barbassa (2003), reduz a percolação das águas pluviais e aumenta o escoamento superficial, impactando diretamente o sistema de microdrenagem e posterior macrodrenagem.

7. quanto ao uso de fontes alternativas para geração de energia: em ambos os conjuntos habitacionais não foram instaladas placas fotovoltaicas para captação de energia solar. Microusinas de energia solar podem viabilizar uma economia considerável na conta de energia (PEREIRA et al., 2017). O montante poderá variar de acordo com irradiação solar global que incide sobre o município e áreas onde as habitações estão construídas. Segundo Pereira et al. (2017), a média anual do total diário da irradiação global horizontal no litoral sul da Bahia está na faixa de 5,0 e $5,25 \mathrm{KWh} / \mathrm{m}^{2} /$ dia. Especificamente no município de Ilhéus, BA, por exemplo, tal média equivale a 4,2 KWh/m²/dia (GOMES et al., 2019). Ou seja, superior às médias anuais de países como Alemanha, França e Espanha que tradicionalmente usam a energia solar como fonte alternativa (CALDAS; MOISÉS, 2016).

8. quanto aos coletores e armazenamento de águas pluviais para reúso não potável: também foi observado que não existem coletores de águas pluviais e armazenamento para reúso em nenhuma das edificações. De acordo com Lima et al. (2011), essa estratégia possibilita uma economia de água que pode chegar até $100 \%$ (em relação ao abastecimento via concessionária) a depender dos índices pluviométricos locais. Pontua-se que os municípios de Ilhéus e Itabuna, BA estão situados numa região cujos índices pluviométricos anuais podem atingir $2.400 \mathrm{~mm}$; as chuvas são regulares durante todo o ano e mais abundantes nos meses que se estendem de maio a agosto (SANTOS; FRANÇA, 2009). Entretanto, mesmo com condições pluviométricas favoráveis, um sistema de coleta e armazenamento de águas pluviais não foi previsto.

9. quanto ao tratamento de resíduos sanitários e domésticos: em ambos os conjuntos habitacionais os resíduos sanitários e de cozinha são coletados e direcionados para o sistema de tratamento convencional de efluentes dos municípios. 


\section{CONCLUSÃO}

Após análise das informações coletadas nos conjuntos habitacionais do PMCMV Residencial Pedro Fontes de Araújo I (Itabuna, BA) e Residencial Rio Cachoeira (Ilhéus, BA), concluiu-se que os resultados não corroboram a hipótese da pesquisa de que o litoral sul da Bahia (onde os municípios de Ilhéus e Itabuna estão situados) por apresentar características biogeoclimáticas que potencializam estratégias projetuais que contemplam aspectos bioclimáticos, contribuiriam para um padrão habitacional do PMCMV pautado na eficiência energética.

Ou seja, os conjuntos habitacionais do PMCMV (para a faixa de 0 a 3 salários mínimos), no litoral sul da Bahia, apresentam padrão arquitetônico que não considera quaisquer peculiaridades ambientais/naturais do local onde foram construídos. Tais empreendimentos são similares aos PMCMVs localizados em outras regióes do país.

De acordo com Conceição, Imai e Urbano (2015) isso ocorre porque os programas governamentais habitacionais continuam reproduzindo soluções projetuais e construtivas já comprovadas como ineficientes. Trata-se de uma padronização arquitetônica das habitações em âmbito nacional. Segundo Boueri Filho, Pedro e Scoaris (2012), tal padronização implica não só na desconsideração dos aspectos ambientais e sociais do local de implantação dos empreendimentos, mas também na redução da área útil das habitações para permitir rápida construção com o menor custo possível.

Dessa forma, a necessidade de construção rápida com o menor custo também inviabiliza novas tecnologias construtivas, uso de materiais alternativos sustentáveis, e estratégias projetuais bioclimáticas mínimas que possibilitariam eficiência energética.

\section{AGRADECIMENTOS}

Ao Conselho Nacional de Desenvolvimento Científico e Tecnológico (CNPq), Instituição de fomento da Pesquisa intitulada: "Habitações de Interesse 
Social e Sustentabilidade: estudos de tipologias arquitetônicas, eficiência energética e avaliação do ciclo de vida dos materiais" contemplado no Edital Universal. Processo: 402387/2016-3.

\section{REFERÊNCIAS}

ASSIS, E. S. de; PEREIRA, E. M. D.; SOUZA, R. V. G. de.; DINIZ, A. S. A. C. Habitação social e eficiência energética: um protótipo para o clima de Belo Horizonte. In: CONGRESSO BRASILEIRO DE EFICIÊNCIA ENERGÉTICA., 2., 2007, Vitória. Anais [...]. [s.1.]: Associação Brasileira de Eficiência Energética, 2007. p. 1-7. Disponível em: https://www.researchgate.net/publication/290436485. Acesso em: 20 out. 2017.

ABNT. NBR 15.220/3: desempenho térmico de edificações. Parte 3: zoneamento bioclimático brasileiro e diretrizes construtivas para habitações unifamiliares de interesse social. Rio de Janeiro: ABNT, 2003.

BOUERI FILHO, J. J.; PEDRO, J. B.; SCOARIS, R. de O. Análise das exigências de área aplicáveis às habitações do programa Minha Casa Minha Vida. Lisboa: LNEC, 2012. Disponível em: http://repositorio.lnec.pt:8080/xmlui/ handle/123456789/1004757. Acesso em: 20 out. 2018.

BALBIM, R.; KRAUSE, C. Produção social da moradia: um olhar sobre o planejamento da habitação de interesse social no Brasil. R. B. Estudos Urbanos e Regionais, v. 16, n. 1, p. 189-201, 2014. DOI: http://dx.doi.org/10.22296/23171529.2014v16n1p189.

BARBOSA, A. da S. R.; BARBIRATO, J. C. C.; SILVA, M. M. C. P. Avaliação do uso de bambu como material alternativo para a execução de habitação de interesse social. Ambiente Construído, v. 8, n. 1, p. 115-129, 2008. Disponível: https://www.seer. ufrgs.br/ambienteconstruido/article/view/3805. Acesso em abr. 2018.

BOHADANA, I. P. B. Avaliação de habitação de interesse social rural construída com fardos de palha, terra e cobertura verde, segundo critérios de sustentabilidade. 2007. 179 f. Dissertação (Mestrado em Engenharia Civil) Universidade Federal do Rio Grande do Sul, Porto Alegre, 2007. 
BRASILEIRO, S. B. de C. Adequação ao selo Casa Azul da Caixa Econômica Federal de edificações do Programa Minha Casa Minha Vida. 2013. 176 f. Dissertação (Mestrado em Engenharia Urbana e Ambiental) - Universidade Federal da Paraíba, João Pessoa, 2013.

CALDAS, H. H. S. e; MOISÉS, A. L. S. Geração fotovoltaica distribuída: estudo de caso para consumidores residenciais de Salvador - BA. Revista Brasileira de Energias Renováveis, v. 5, p. 164-180, 2016. Disponível em: https://revistas.ufpr.br/rber/ article/view/45270/pdf. Acesso em: 20 set. 2018.

CARVALHO, M. T. M.; SPOSTO, R. M. Metodologia para avaliação da sustentabilidade de habitações de interesse social com foco no projeto. Ambiente Construído, v. 12, n. 1, p. 207-225, jan./mar. 2012. Disponível em: http://www.scielo.br/pdf/ac/v12n1/ v12n1a14. Acesso em: jun. 2018.

CARVALHO, A. W. B.; STEPHAN, I. I. C. Eficácia social do Programa Minha Casa Minha Vida: discussão conceitual e reflexões a partir de um caso empírico. Cadernos Metrópole, v. 18, n. 35, p. 283-307, 2016. DOI: http://dx.doi.org/10.1590/22369996.2016-3513.

CONCEIÇÃO, P. A.; IMAI, C.; URBANO, M. R. Captura e hierarquização de requisitos do cliente de habitação de interesse social a partir da avaliação pós-ocupação e da técnica de preferência declarada. Gestão e Tecnologia de Projetos, v. 10, n. 1, p. 79-98, 2015. DOI: http://dx.doi.org.br/10.11606/gtp.v10i1.98795.

CORBELLA, O.; CORNER, V. Manual de arquitetura bioclimática tropical para redução do consumo energético. Rio de Janeiro: Editora Revan, 2011. 112 p.

CORBELLA, O.; YANNAS, S. Em busca de uma arquitetura sustentável para os trópicos: conforto ambiental. Rio de Janeiro: Editora Revan, 2009. 305 p.

COTA, D. A.; SILVA, A. L. A. Programa "Minha Casa, Minha Vida" (faixa 1) em São João Del Rei, MG: uma análise crítica. Revista do Programa de Pós-Graduação em Geografia, v. 8, n. 2, p. 140-162, 2016. Disponível em: http://periodicos.uem.br/ojs/ index.php/Geoinga/article/view/37951. Acesso em: jun. 2018.

DURAN, S. C. Architecture and energy efficiency. Barcelona: FKG, 2011. 383 p. 
FONTES, A. R. M.; BARBASSA, A. P. Diagnóstico e prognóstico da ocupação e da impermeabilização urbanas. Revista Brasileira de Recursos Hídricos, v. 8, n. 2, p. 137-147, 2003. Disponível em: https:/www.researchgate.net/profile/Ademir Barbassa/publication/228432786_Diagnostico_e_prognostico_da_ocupacao_e_ impermeabilizacao_urbanas/links/565f2acb08aeafc2aaca3344/Diagnostico-eprognostico-da-ocupacao-e-impermeabilizacao-urbanas.pdf. Acesso em: out. 2017.

FOSTER, W.; HAWKES, D. Energy efficient buildings: architecture, engineering, and environment. New York: W. W. Norton \& Company, 2002. 239 p.

FUNDAÇÃO JOÃO PINHEIRO. Déficit habitacional no Brasil 2013-2014. Belo Horizonte: Fundação João Pinheiro, 2016. Disponível em: http://fjp.mg.gov.br/ index.php/produtos-e-servicos1/2742-deficit-habitacional-no-brasil-3. Acesso em: set. 2017.

GOMES, R. L.; CERQUEIRA, A. H.; STRENZEL, G. M. R.; PEREIRA, Y da C. Mapping of solar potential for electric micro-generation: the case of the city of Ilhéus. Sociedade \& Natureza, v. 31, n. 1, p. 14-23, 2019. DOI: http://dx.doi.org/10.14393/ SN-v31n1-2019-42302

GRÜNBERG, P. R. M.; MEDEIROS, M. H. F. de; TAVARES, S. F. Certificação ambiental de habitações: comparação entre LEED for Homes, Processo Aqua e Selo Casa Azul. Ambiente \& Sociedade, v. 17, n. 2, p. 195-214, 2014. Disponível em: http://www. scielo.br/pdf/asoc/v17n2/a13v17n2.pdf. Acesso em: set. 2017.

KIBERT, C. J. Sustainable construction: green building design and delivery. New Jersey: John Wiley \& Sons Inc, 2013.

KRÜGER, E. L.; LAROCA, C. Avaliação de desempenho térmico de protótipo de baixo custo em madeira de reflorestamento. Rem: Revista Escola de Minas, v. 62, n. 4, p. 447-454, dez. 2009. Disponível em: https://www.researchgate.net/ publication/250037287_Avaliacao_de_desempenho_termico_de_prototipo_de_ baixo_custo_em_madeira_de_reflorestamento. Acesso em: set. 2017.

LIMA, J. A. de; DAMBROS, M. V. R.; ANTONIO, M. A. P. M de; JANZEN, J. G.; MARCHETTO, M. Potencial da economia de água potável pelo uso de água pluvial: análise de 40 cidades da Amazônia. Revista Engenharia Sanitária e Ambiental, 
v. 16, n. 3, p. 291-298, jul./set. 2011. Disponível em: http://www.scielo.br/pdf/esa/ v16n3/v16n3a12. Acesso em: abr. 2018.

MACHADO, R. M. e S.; VAGHETTI, M. A. O. Casa popular eficiente: desempenho térmico durante o inverno.In: CONGRESSO TÉCNICO CIENTÍIFICO DAENGENHARIA E DA AGRONOMIA, 2015. Anais [...]. [Brasília]: Conselho Federal de Engenharia e Agronomia, 2015. p. 1-4.

MARCENA, E. M.; SILVA, E. S.; GIACOMINI, M. H.; SANTOS, L. C. Dos; D’ALOIA G., R. Água de uso doméstico, captação e reutilização. Integrada Revista Científica, v. 4, p. 93-129, 2017. Disponível em: http://facol.br/revista/pdf/5b732e18a758d_v4 n1_2017_artigo.5.pdf. Acesso em: 20 fev. 2018.

MEDEIROS RAPOSO, L. C. M. M. Habitação e desenvolvimento urbano - uma análise introdutória da implementação da arborização urbana no âmbito do Programa Minha Casa Minha Vida. In: CONGRESSO BRASILEIRO DE ARBORIZAÇÃO URBANA, 18., 2014, Rio de Janeiro. Anais [...]. [s. l.]: [s. n], [2014]. p. 1-7. Disponível: http:// sbau.web2204.uni5.net/Arquivos/21358.pdf. Acesso em abr. 2018.

MORAIS, J. M. da S. C. Ventilação natural em edifícios multifamiliares do "Programa Minha Casa Minha Vida". 229 f. 2013. Tese (Doutorado em Arquitetura Tecnologia e Cidade) - Faculdade de Engenharia Civil, Arquitetura e Urbanismo, Universidade Estadual de Campinas, Campinas, 2013.

MORAIS, J. M. da S. C.; LABAKI, L. C. CFD como ferramenta para simular ventilação natural interna por ação dos ventos: estudos de caso em tipologias verticais do "Programa Minha Casa, Minha Vida". Ambiente Construído, v. 17, n. 1, p. 223-244, 2017. DOI: http://dx.doi.org/10.1590/s1678-86212017000100133.

OLIVEIRA, E. W. N. de. Telhados verdes para habitações de interesse social: retenção das águas pluviais e conforto térmico. 2009. 87 f. Dissertação (Mestrado em Engenharia Ambiental) - Universidade do Estado do Rio de Janeiro, Rio de Janeiro, 2009.

ORLEBEKE, C. J. The evolution of low-income housing policy, 1949 to 1999. Housing Policy Debate, v. 11, n. 2, p. 489-520, 2010. DOI: https://doi.org/10.1080 $/ 10511482.2000 .9521375$. 
PEREIRA, E. B. et al. Atlas brasileiro de energia solar. São José dos Campus: INPE, 2017. $88 \mathrm{p}$.

PROVENZANO, D. de C.; BASTOS, L. E. G. Avaliação da sustentabilidade de um empreendimento de HIS do PMCMV, através do Selo Casa Azul. Mix Sustentável, v. 3, n. 2, p. 14-23, 2017. DOI: https://doi.org/10.29183/2447-3073.MIX2017.

REIS, A. T. da L.; LAYS, M. C. D. O projeto da habitação de interesse social e a sustentabilidade social. Ambiente Construído, v. 10, n. 3, p. 99-119, 2010. DOI: http://dx.doi.org/10.1590/S1678-86212010000300007.

RAMOS, J. da S.; NÓIA, A. C. Análise da execução do Programa Minha Casa Minha Vida nos municípios de Ilhéus e Itabuna, Bahia. In: SEMANA DO ECONOMISTA, 4., ENCONTRO DE EGRESSOS, 4., 2014, Ilhéus. Anais [...]. Ilhéus, BA: Universidade Estadual de Santa Cruz, 2014. p. 1-20. Disponível em: http://www.uesc.br/eventos/ ivsemeconomista/anais/gt1-1.pdf. Acesso em: dez. 2017.

RIOS, G. A. de A. Desempenho termoenergético de habitação de interesse social. 2015. 150 f. Tese (Doutorado em Engenharia Elétrica) - Universidade Estadual Paulista, Ilha Solteira, 2015.

ROCHA, F. M. D.; MELO, A. B.; SILVA, E. P.; TORRES, S. M. Pré-moldado (bloco EVAi) para alvenaria intertravada: projeto, produção, desempenho e simulação de uso em habitação social. Ambiente Construído, v. 13, n. 2, p. 47-60, 2013. DOI: http:// dx.doi.org/10.1590/S1678-86212013000200005.

ROLNIK, R. et al. O Programa Minha Casa Minha Vida nas regióes metropolitanas de São Paulo e Campinas: aspectos socioespaciais e segregação. Cadernos Metrópole, v. 17, n. 33, p. 127-154, 2015. DOI: http://dx.doi.org/10.1590/2236-9996.2015-330.

RUBIN, G. R. Movimento moderno e habitação social no Brasil. Geografia Ensino \& Pesquisa, v. 17, n. 2, p. 57-71, 2013. DOI: 10.5902/2236499410772.

SALATI, E. Controle de água através de Sistemas de Wetlands construídos. Rio de Janeiro: Fundação Brasileira para o Desenvolvimento Sustentável, 2006. 19 f. Disponível em: http://www.fbds.org.br/Apresentacoes/Controle_Qualid_Agua_ Wetlands_ES_out06.pdf. Acesso em: jun. 2018. 
SANTESSO, C. A.; MORAES, C. S. B. de; SANTARINE, G. A; GONÇALVES, J. C. Economia de energia através de estratégias passivas e ativas: um estudo para habitação de interesse social. Revista Espacios, v. 38, n. 23, p. 1-23, 2017. Disponível em: http:// www.revistaespacios.com/a17v38n23/a17v38n23p23.pdf. Acesso em: jun. 2018.

SANTOS, A. A. P. dos; FRANÇA, S. Caracterização espaço-temporal do regime pluviométrico da Região Sul da Bahia. In: Seminário de Pós-Graduação da UNESP Rio Claro. Anais do Seminário de Pós-Graduação da UNESP Rio Claro, p. 14-33, 2009. Disponível em: http://www.sbagro.org.br/bibliotecavirtual/arquivos/3695.pdf. Acesso em: dez. 2017.

SANTOS, K. F dos.; OLIVEIRA, D, M. de.; NUNES, L. A. M. Sustentabilidade na construção de residências para o projeto "Minha Casa Minha Vida". In: CONGRESSO NACIONAL DE EXCELÊNCIA EM GESTÃO, 10., 2014, Rio de Janeiro. Anais [...]. [s. l.]: [s. n.], 2014. p. 1-14. Disponível em: http://www.inovarse.org/sites/default/files/ T14_0403_3.pdf. Acesso em: abr. 2018.

SANTOS, R. L. dos.; SANTANA, J. C. S. Materiais de construção sustentáveis em empreendimentos de habitação de interesse social financiados pelo PMCMV. Mix Sustentável, v. 3, n. 3, p. 49-58, 2017. Disponível em: http://www.nexos.ufsc.br/ index.php/mixsustentavel/article/view/1892. Acesso em: 20 jul. 2018.

SARAMAGO, R. de C.; VILLA, S. B. Estratégias de sustentabilidade para habitação social: a experiência do Projeto MORA. In: ENCONTRO NACIONAL DE CONFORTO NO AMBIENTE CONSTRUÍDO, 12., ENCONTRO LATINOAMERICANO DE CONFORTO NO AMBIENTE CONSTRUÍDO, 8., 2013, Brasília. Anais [...]. Brasília: Universidade de Brasília, 2013. p. 1-10.

SOBREIRA, F.; FELIX, B. Projetos de habitação social no Brasil: discurso e prática da sustentabilidade. Universitas: Arquitetura e Comunicação Social, v. 10, n. 2, p. 23-35, 2013. DOI: http://dx.doi.org/10.5102/uc.v10i2.2569.

SOUZA, M. C. de; GRIGOLETTI, G; VAGHETTI, M. O. Avaliações dinâmicas da iluminação natural em protótipo de habitação de interesse social. In: ENCONTRO NACIONAL DE CONFORTO NO AMBIENTE CONSTRUÍDO, 14., ENCONTRO LATINOAMERICANO DE CONFORTO NO AMBIENTE CONSTRUÍDO, 10., 2017, Balneário Camboriú. Anais [...]. Balneário Camboriú, SC: Associação Nacional de 
Tecnologia do Ambiente Construído, 2017. p. 1713-1719.

SOUZA, E. L.; SUGAI, M. I. Minha Casa Minha Vida: periferização, segregação e mobilidade intraurbana na área conurbada de Florianópolis. Cadernos Metrópole, v. 20, n. 41, p. 75-98, 2018. DOI: http://dx.doi.org/10.1590/2236-9996.2018-4104.

SPOSTO, R. M.; PAULSEN, J. S. Energia incorporada em habitações de interesse social na fase de pré-uso: o caso do Programa Minha Casa Minha Vida no Brasil. Oculum Ensaios, v. 11, n. 1, p. 39-50, 2014. Disponível em: http://periodicos.puc-campinas. edu.br/seer/index.php/oculum/article/viewFile/2281/1818. Acesso em: 20 jul. 2018.

TRANFIELD, D.; DENYER, D.; SMART, P. Towards a Methodology for Developing Evidence-Informed Management Knowledge by Means of Systematic Review. British Journal of Management, v. 14, p. 207-222, 2003. Disponível em: https:// www.cebma.org/wp-content/uploads/Tranfield-et-al-Towards-a-Methodology-forDeveloping-Evidence-Informed-Management.pdf. Acesso em: out. 2017.

VISINTAINER, M. R. M.; CARDOSO, L. A.; VAGHETTI, M. A. O. Habitação popular sustentável: sustentabilidade econômica e ambiental. Revista de Arquitetura da IMED, v. 1, n. 2, p. 133-140, 2012. Disponível em: https://seer.imed.edu.br/index. php/arqimed/article/viewFile/416/333. Acesso em: 20 out. 2017.

Recebido em: 26/04/2019 Aceito em: 23/05/2019 
Anexo 1. Roteiro de observação direcionado para análise dos conjuntos habitacionais selecionados durante a pesquisa

\begin{tabular}{|c|c|}
\hline \multicolumn{2}{|c|}{ Nome do conjunto habitacional: } \\
\hline \multicolumn{2}{|l|}{ Endereço: } \\
\hline \multicolumn{2}{|c|}{ Ano de ocupação dos apartamentos: } \\
\hline \multicolumn{2}{|c|}{ Área do apartamento: } \\
\hline \multicolumn{2}{|c|}{ 1) Implantação do conjunto habitacional } \\
\hline $\begin{array}{c}\text { Características do } \\
\text { terreno }\end{array}$ & $\begin{array}{l}\text { ( ) plano } \\
\text { ( ) acidentado } \\
\text { ( ) plano com algumas áreas acidentadas }\end{array}$ \\
\hline $\begin{array}{l}\text { Implantação das edi- } \\
\text { ficações (em caso de } \\
\text { terrenos acidenta- } \\
\text { dos ou parcialmente } \\
\text { acidentados) }\end{array}$ & $\begin{array}{l}\text { ( ) o conjunto habitacional foi construído considerando a topografia local, } \\
\text { seguindo o desenho natural das curvas de nível e sem grande movimenta- } \\
\text { ção de terra (corte e aterro) - apresenta alguns taludes } \\
\text { ( ) o conjunto habitacional foi construído considerando parcialmente a } \\
\text { topografia local, com movimentação de terra parcial (corte e aterro) - apre- } \\
\text { senta muros de contenção e taludes } \\
\text { ( ) houve cortes e aterros suficientes para desconfigurar por completo a } \\
\text { topografia natural do terreno }\end{array}$ \\
\hline $\begin{array}{l}\text { Insolação e ventos } \\
\text { dominantes }\end{array}$ & $\begin{array}{l}\text { ( ) as edificações foram construídas voltadas predominantemente para o } \\
\text { nascente } \\
\text { ( ) as edificações foram construídas voltadas predominantemente para o } \\
\text { poente } \\
\text { ( ) as edificações foram construídas considerando a direção dos ventos } \\
\text { dominantes } \\
\text { ( ) as edificações não foram construídas considerando a direção dos ven- } \\
\text { tos dominantes }\end{array}$ \\
\hline $\begin{array}{c}\text { Distância em relação } \\
\text { ao centro urbano do } \\
\text { município }\end{array}$ & $\begin{array}{l}\text { ( ) O conjunto habitacional localiza-se nas imediações do centro urbano } \\
\text { do município } \\
\text { ( ) O conjunto habitacional localiza-se em área periférica próxima ao cen- } \\
\text { tro urbano do município, a cerca de } 5 \mathrm{~km} \\
\text { ( ) O conjunto habitacional localiza-se em área periférica ao centro urbano } \\
\text { do município, a cerca de } 10 \mathrm{~km} \\
\text { ( ) O conjunto habitacional localiza-se em área periférica ao centro urbano } \\
\text { do município, a cerca de } 15 \mathrm{~km} \text { ou mais }\end{array}$ \\
\hline & \\
\hline
\end{tabular}




\begin{tabular}{|c|c|}
\hline $\begin{array}{l}\text { Locação das abertu- } \\
\text { ras (janelas) } \\
\text { OBS: janela tama- } \\
\text { nho padrão: } 1,20 \mathrm{~m} \\
\text { (larg) X } 1,20 \mathrm{~m} \text { (alt), } \\
\text { parapeito }=1,00 \mathrm{~m} \\
\text { Tipologia: correr }\end{array}$ & $\begin{array}{l}\text { ( ) Todos os ambientes possuem janelas voltadas para o exterior da edifi- } \\
\text { cação } \\
\text { ( ) Um dos ambientes possui janela voltada para o interior da edificação } \\
\text { ( ) Dois ambientes possuem janelas voltadas para o interior da edificação } \\
\text { ( ) Três ambientes ou mais possuem janelas voltadas para o interior da } \\
\text { edificação }\end{array}$ \\
\hline $\begin{array}{l}\text { Ventilação cruzada } \\
\text { OBS: porta padrão: } \\
0,90 \text { m (larg) X 2,10 } \\
\text { m (alt) } \\
\text { Tipologia: abrir }\end{array}$ & $\begin{array}{l}\text { ( ) portas e janelas instaladas de modo a permitir ventilação cruzada } \\
\text { ( ) portas e janelas instaladas de modo a permitir parcialmente ventilação } \\
\text { cruzada } \\
\text { ( ) os locais onde as portas e janelas foram instaladas não permitem ven- } \\
\text { tilação cruzada }\end{array}$ \\
\hline $\begin{array}{l}\text { Presença de abertu- } \\
\text { ras superiores (pró- } \\
\text { ximas ao teto) para } \\
\text { saída do ar quente } \\
\text { OBS: Janela tipo } \\
\text { maximar: } 0,90 \mathrm{~m} \\
\text { (larg) X 0,60 m (alt) } \\
\text { ou ocupando toda } \\
\text { extensão superior } \\
\text { da parede do cô- } \\
\text { modo }\end{array}$ & $\begin{array}{l}\text { ( ) Existem aberturas superiores em todos os ambientes para saída do ar } \\
\text { quente e melhoria da ventilação cruzada } \\
\text { ( ) Existem aberturas superiores em um ou dois ambientes para saída do } \\
\text { ar quente e melhoria da ventilação cruzada } \\
\text { ( ) Não existem aberturas superiores no apartamento para saída do ar } \\
\text { quente e melhoria da ventilação cruzada }\end{array}$ \\
\hline \multicolumn{2}{|r|}{ 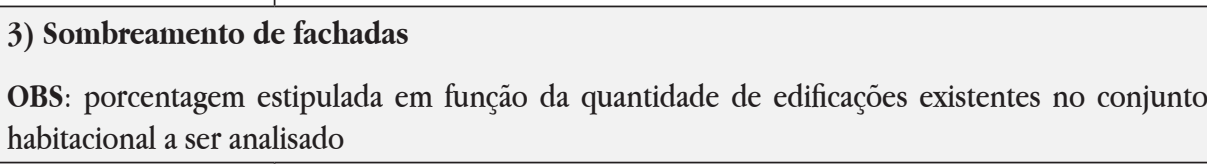 } \\
\hline Brise soleil & $\begin{array}{l}\text { ( ) Existe brise soleil em todas as fachadas das edificações do conjunto } \\
\text { habitacional que recebem maior incidência solar direta } \\
\text { ( ) Existe brise soleil em cerca de } 50 \% \text { das fachadas das edificações do } \\
\text { conjunto habitacional que recebem maior incidência solar direta } \\
\text { ( ) Existe brise soleil em cerca de } 25 \% \text { das fachadas das edificações do } \\
\text { conjunto habitacional que recebem maior incidência solar direta } \\
\text { ( ) Não existe brise soleil nas fachadas das edificações do conjunto habita- } \\
\text { cional que recebem maior incidência solar direta }\end{array}$ \\
\hline
\end{tabular}




\begin{tabular}{|c|c|}
\hline Fachad & $\begin{array}{l}\text { ( ) Existe fachada verde em todas as faces das edificações do conjunto } \\
\text { habitacional que recebem maior incidência solar direta } \\
\text { ( ) Existe fachada verde em cerca de } 50 \% \text { das faces das edificações do con- } \\
\text { junto habitacional que recebem maior incidência solar direta } \\
\text { ( ) Existe fachada verde em cerca de } 25 \% \text { das faces das edificações do con- } \\
\text { junto habitacional que recebem maior incidência solar direta } \\
\text { ( ) Não existe fachada verde nas faces das edificações do conjunto habita- } \\
\text { cional que recebem maior incidência solar direta }\end{array}$ \\
\hline \multicolumn{2}{|c|}{ 4) Materiais usados na construção } \\
\hline $\begin{array}{l}\text { Paredes e acaba- } \\
\text { mento }\end{array}$ & $\begin{array}{l}\text { ( ) Paredes construídas em alvenaria de blocos cerâmicos com acabamento } \\
\text { em chapisco, reboco e pintura } \\
\text { ( ) Paredes construídas em alvenaria de blocos de concreto com acabamen- } \\
\text { to em reboco e pintura } \\
\text { ( ) Paredes construídas em alvenaria de blocos de concreto sem acaba- } \\
\text { mento } \\
\text { ( ) Outro }\end{array}$ \\
\hline $\begin{array}{c}\text { Paredes em áreas } \\
\text { molhadas }\end{array}$ & $\begin{array}{l}\text { ( ) Paredes com revestimento cerâmico com altura variando de } 1,50 \mathrm{~m} \text { a } \\
2,10 \mathrm{~m} \\
\text { ( ) Paredes com revestimento cerâmico até o teto } \\
\text { ( ) Paredes sem revestimento cerâmico } \\
\text { ( ) Outro }\end{array}$ \\
\hline Piso & $\begin{array}{l}\text { ( ) Piso cerâmico tipo A com rejunte } \\
\text { ( ) Piso cerâmico tipo B com rejunte } \\
\text { ( ) Piso cerâmico tipo C com rejunte } \\
\text { ( ) Piso em cimento queimado colorido ou na cor natural com acabamento } \\
\text { em resina } \\
\text { ( ) Piso em parquet (madeira) } \\
\text { ( ) Carpete de madeira } \\
\text { ( ) Carpete de tecido } \\
\text { ( ) Outro }\end{array}$ \\
\hline
\end{tabular}




\begin{tabular}{|c|c|}
\hline Janelas & $\begin{array}{l}\text { ( ) Esquadrias em alumínio com vidro e veneziana } \\
\text { ( ) Esquadrias em alumínio com vidro sem veneziana } \\
\text { ( ) Esquadrias em aço galvanizado com vidro e veneziana } \\
\text { ( ) Esquadrias em aço galvanizado com vidro sem veneziana } \\
\text { ( ) Esquadrias em madeira com vidro e acabamento com verniz ou pintura } \\
\text { e veneziana } \\
\text { ( ) Esquadrias em madeira com vidro e acabamento com verniz ou pintura, } \\
\text { sem veneziana } \\
\text { ( ) Outro }\end{array}$ \\
\hline Portas & $\begin{array}{l}\text { ( ) Porta de madeira com acabamento em verniz ou pintura } \\
\text { ( ) Porta de madeira semi-oca com acabamento em verniz ou pintura } \\
\text { ( ) Porta de alumínio tipo veneziana } \\
(\quad \text { ) Outro }\end{array}$ \\
\hline Teto e acabamento & $\begin{array}{l}\text { ( ) Laje pré-moldada de tijolos cerâmicos com acabamento em chapisco, } \\
\text { reboco e pintura } \\
\text { ( ) Laje pré-moldada de tijolos cerâmicos com acabamento em chapisco } \\
\text { e pintura } \\
\text { ( ) Laje pré-moldada de blocos de concreto com acabamento em chapisco, } \\
\text { reboco e pintura } \\
\text { ( ) Laje pré-moldada de blocos de concreto com acabamento em chapisco } \\
\text { e pintura } \\
\text { ( ) Laje pré-moldada de blocos de concreto sem acabamento } \\
\text { ( ) Outro }\end{array}$ \\
\hline
\end{tabular}




\begin{tabular}{|c|c|}
\hline $\begin{array}{c}\text { Vegetação natural e/ } \\
\text { ou introduzida }\end{array}$ & $\begin{array}{l}\text { ( ) parte da vegetação natural (de médio e grande portes) foi mantida após } \\
\text { a construção das edificações } \\
\text { ( ) não há resquícios da vegetação natural (de médio e grande portes) } \\
\text { ( ) há áreas destinadas ao plantio de vegetação de médio e grande portes } \\
\text { ( ) não há áreas destinadas ao plantio de vegetação de médio e grande } \\
\text { portes } \\
\text { ( ) há áreas destinadas ao plantio de vegetação de pequeno porte (arbustos } \\
\text { e grama) } \\
\text { ( ) não há áreas destinadas ao planto de vegetação de pequeno porte (ar- } \\
\text { bustos e grama) } \\
\text { ( ) há áreas destinadas apenas ao plantio de grama }\end{array}$ \\
\hline Telhado verde & $\begin{array}{l}\text { ( ) A cobertura das edificações apresenta de } 5 \text { a } 25 \% \text { de área com telhado } \\
\text { verde } \\
\text { ( ) A cobertura das edificações apresenta de } 25 \text { a } 50 \% \text { de área coberta com } \\
\text { telhado verde } \\
\text { ( ) A cobertura das edificações apresenta de } 50 \text { a } 75 \% \text { de área coberta com } \\
\text { telhado verde } \\
\text { ( ) A cobertura das edificações apresenta } 75 \% \text { ou mais de área coberta com } \\
\text { telhado verde } \\
\text { ( ) Não existem áreas cobertas com telhado verde }\end{array}$ \\
\hline \multicolumn{2}{|c|}{ 6) Tipo de pavimentação (percolação das águas pluviais) } \\
\hline Vias de acesso & $\begin{array}{l}\text { ( ) pavimentação com asfalto (impermeabilizado) } \\
\text { ( ) pavimentação com piso intertravado e similares (permite percolação } \\
\text { das águas pluviais) } \\
\text { ( ) Outro }\end{array}$ \\
\hline Calçadas & $\begin{array}{l}\text { ( ) calçada de cimento contínua com juntas secas de dilatação (imper- } \\
\text { meabilizada) } \\
\text { ( ) calçada de cimento em placas distantes umas das outras cerca de } 3 \mathrm{~cm} \text {, } \\
\text { com areia ou grama entre as placas (permite percolação das águas pluviais) } \\
\text { ( ) calçada de piso intertravado ou similar (permite percolação das águas } \\
\text { pluviais) } \\
\text { ( ) Outro }\end{array}$ \\
\hline
\end{tabular}


7) Uso de fontes alternativas de energia (energia solar em concomitância com o fornecimento de energia via concessionária)

OBS: porcentagem estipulada em função da quantidade de edificações existentes no conjunto habitacional a ser analisado

Cobertura (existência de placas fotovoltaicas)

( ) A cobertura das edificações apresenta de 5 a 25\% de área coberta com placas fotovoltaicas

( ) A cobertura das edificações apresenta de 25 a 50\% de área coberta com placas fotovoltaicas

( ) A cobertura das edificações apresenta de 50 a 75\% de área coberta com placas fotovoltaicas

( ) A cobertura das edificações apresenta $75 \%$ ou mais de área coberta com placas fotovoltaicas

( ) Não existem placas fotovoltaicas instaladas

\section{8) Coletores de águas pluviais para reúso não potável}

OBS: porcentagem estipulada em função da quantidade de edificações existentes no Conjunto Habitacional a ser analisado

\begin{tabular}{|c|c|}
\hline $\begin{array}{l}\text { Coletores e armaze- } \\
\text { namento das águas } \\
\text { pluviais para reúso- } \\
\text { reúso }\end{array}$ & $\begin{array}{l}\text { ( ) Existem coletores de águas pluviais para reúso em } 100 \% \text { da cobertura } \\
\text { das edificações do conjunto habitacional } \\
\text { ( ) Existem coletores de águas pluviais para reúso em } 50 \% \text { da cobertura das } \\
\text { edificações do conjunto habitacional } \\
\text { ( ) Existem coletores de águas pluviais para reúso em } 25 \% \text { da cobertura das } \\
\text { edificações do conjunto habitacional } \\
\text { ( ) Não existem coletores de águas pluviais para reúso na cobertura das } \\
\text { edificações do conjunto habitacional }\end{array}$ \\
\hline $\begin{array}{l}\text { Uso da água co- } \\
\text { letada para fins } \\
\text { não potáveis (caso } \\
\text { existam coletores e } \\
\text { armazenamento das } \\
\text { águas pluviais para } \\
\text { reúsoreúso) }\end{array}$ & $\begin{array}{l}\text { ( ) As águas pluviais coletadas são usadas para irrigação dos jardins } \\
\text { ( ) As águas pluviais coletadas são usadas para descargas de bacias sanitá- } \\
\text { rias e mictórios } \\
\text { ( ) As águas pluviais coletadas são usadas para abastecer o reservatório de } \\
\text { combate a incêndio }\end{array}$ \\
\hline
\end{tabular}




\begin{tabular}{|c|l|}
\hline \multirow{2}{*}{$\begin{array}{c}\text { Coleta e sistema de } \\
\text { tratamento }\end{array}$} & $\begin{array}{l}\text { ( ) Resíduos sanitários e da caixa de gordura coletados e direcionados para } \\
\text { tratamento convencional de efluentes do município } \\
\text { ( ) Resíduos sanitários e da caixa de gordura coletados e direcionados para } \\
\text { sistema de fossa e sumidouros sem tratamento } \\
\text { ( ) Resíduos sanitários e da caixa de gordura coletados e tratados in loco } \\
\text { via Wetlands } \\
\text { ( ) Resíduos sanitários e da caixa de gordura coletados e despejados em } \\
\text { vala a céu aberto }\end{array}$ \\
\hline \multirow{2}{*}{ Observações gerais } & \\
\cline { 2 - 3 } & \\
\hline
\end{tabular}

